\title{
AMP-deaminase in elasmobranch fish: A comparative histochemical and enzymatic study
}

\author{
Marie T. Thébault ${ }^{\mathbf{a},{ }^{\star},}$ Lahoucine Izem ${ }^{\mathbf{b}}$, Jean Paul Leroy ${ }^{\mathbf{c}}$, Eric Gobin', \\ Gregory Charrier $^{\mathrm{a}}$ and Jean Paul Raffin ${ }^{\mathrm{d}}$
}

\footnotetext{
a LEMAR, UMR CNRS 6539, Université de Bretagne Occidentale, Institut Universitaire Européen de la Mer, Place Copernic, Technopole Brest-Iroise, 29 280, Plouzané, France

${ }^{\mathrm{b}}$ Station de Biologie Marine du Museum National d'Histoire Naturelle et du Collège de France, Concarneau, France

${ }^{\mathrm{C}}$ Laboratoire d'Anatomie-pathologie, CHU Morvan, 29609, Brest-Cedex, France

d Laboratoire de Microbiologie des Milieux Extrêmes, UMR 6197, IFREMER, B.P. 70, 29280 Plouzané Cedex, France

*: Marie-Therese.Thebault@univ-brest.fr Tel.: +33 2984986 12; fax: +33 298498645.
}

\begin{abstract}
AMP-deaminase activity was measured in white muscle from a wide range of fish, including one cyclostome, 13 chondrosteans, and one teleost to elucidate the pattern of the AMP-deaminase activity in white muscle of fish. Compared to a mammalian (rat) muscle extract, low enzyme activities are found in the cyclostome and two elasmobranchs from two families (Scyliorhinidae, Hexanchidae). In contrast, higher AMP-deaminase activities, similar to mammals, are expressed in Squalidae, all families of skates, Chimaeridae and in the teleostean fish. We then compared AMP-deaminase activities in red and white muscles from two representative elasmobranch fish, the dogfish (Scyliorhinus canicula) and the thornback ray (Raja clavata). The fibre type composition and distribution of the locomotory musculature were determined in these two elasmobranchs to establish a relationship between the morphology, the type of fibres of the locomotion-implicated muscles and the AMP-deaminase activity. Experimental data are discussed with respect to the layout of fibres in the myotome. In both species, three fibre types were identified. In the two fish myotomes, most of the axial muscles are white fibres while red fibres constitute a thin sheet. Some differences were observed between the two species in the distribution of intermediate fibres: in dogfish, these are located between the red and white fibres; in thornback ray, some are dispersed within the white fibre region, while others form an intermediary layer like in dogfish. These results suggest that in the course of evolution, an amplification of the AMP-deaminase activity in muscle was coupled with increase of complexity of the muscular structure.
\end{abstract}

Keywords: AMP-deaminase; Elasmobranch; Evolution; Fish; Histology; Muscle; Red fibres; White fibres 


\section{INTRODUCTION}

The locomotory musculature of mammals, amphibians and birds contains a complex distribution of several fibre types classified into three types (I, IIA and IIB), which differ in mean size and in staining properties (Burke et al. 1971, Lannergreen and Hoh 1984, Rowlerson and Spurway 1985, Chayen et al. 1987). On the basis of some enzyme activities, type I fibers, also called slow twitch fibres, have a slow contraction velocity, are very resistant to fatigue and have a high capacity to generate ATP by oxidative metabolic processes. Type IIA fibres, also called fast oxidative fibres, have a fast contraction velocity and a very high capacity for generating ATP mainly by oxidative metabolic processes, and are resistant to fatigue. Type IIB fibres, also called fast glycolytic fibres, contain relatively few mitochondria, fatigue easily, and generate ATP mainly by anaerobic metabolic processes. Fish differ considerably in the organization of muscular system and metabolic processes between the three types. Indeed, the body musculature is myomeric, and different fibre types, rather than being intermixed as in mammals, occupy distinct areas (Johnston 1981). The red ones (slow fibres), in more taxonomically primitive groups of fish, form a thin superficial layer under the skin, whereas the white ones (fast fibres) are involved in the constitution of the trunk muscles (Bone 1966). Intermediate fibres, displaying different diameters and histochemical properties, form an intermediary layer.

In mammals, there are multiple tissue-specific AMP-deaminase isoenzymes which can be distinguished by immunological, kinetic and chromatographic criteria (Ogasawara et al. $1972,1975,1978)$ and the concentration of the enzyme found in skeletal muscle is 
considerably higher than in other tissues (Lowenstein 1972). AMP-deaminase (EC 3.5.4.6) concentration is high in the white fibres (Purzycka 1962). Red muscle also showed high AMP-deaminase activity, but it was about a half of the activity observed in white muscle (Raggi et al. 1969, Fishbein et al. 1979, Ogasawara et al. 1983). Like higher vertebrates, the teleost fish display high AMP-deaminase activities in their white fibres (Kaletha et al. 1991, Raffin et al. 1993). In contrast, a previous report described a low AMP-deaminase activity in white fibres of the dogfish Scyliorhinus canicula (Raffin and Leray 1980). AMP-deaminase activity in red muscles was earlier studied in carp (Van Waarde and Kesbeke, 1981). To our knowledge, the activity of the enzyme in elasmobranch fish red muscle has not been investigated up to now.

Amplification of the AMP-deaminase activity in the white muscle of vertebrates, and especially its significance, has been widely debated. Red and white muscles are known to function in steady-state and burst movements, respectively, and to be different in their metabolic patterns. White muscle is, indeed, known to have a limited oxidative capacity, and inside its ATP generation is highly dependent upon anaerobic metabolism. So, its high content in AMP-deaminase is probably related to the stabilizing function of this enzyme in the regulation of adenine nucleotides metabolism during intense energy demand; it would be done through the stabilization of the adenylate energy charge, the ATP-to-ADP ratio and phosphorylation potential (Lowenstein 1972, Chapman and Atkinson 1973, Veech et al. 1979, Meyer and Terjung 1980, Van Waarde 1988).

The present study was aimed at (1) precising the pattern of AMP-deaminase activity in white muscle of fish, by measuring the activity of enzyme in a wide range of fish, including one cyclostom, 13 chondrosteans, and one teleost, (2) establishing a 
relationship between the morphology, the types of fibres of the locomotion-implicated muscles, and the AMP-deaminase activity, by studying the histological picture of the white muscle on two representative species of benthic elasmobranch, the dogfish Scyliorhinus canicula and the rayfish Raja clavata. Results are discussed in relation with the AMP-deaminase activity displayed by the white fibres as well as the way they are laid out in the myotome. 


\section{MATERIALS AND METHODS}

\section{Animals}

Cyclostoms were obtained from a local fishery in Gironde (France). Rainbow trout were obtained from a local hatchery near Concarneau (France). Rats (Wistar) were purchased from the Centre d'Elevage Janvier (Le Genest St-Isle, France). Chondrostean fish were caught by trawling in the gulf of Gascogne during 1 month IFREMER campaign (EVOE 882), or obtained from from local sellers (Brest, France). Muscle samples were taken immediately, frozen in liquid nitrogen, and kept at $-80^{\circ} \mathrm{C}$ until AMP-deaminase assay.

Specimens of dogfish (Scyliorhinus canicula) and rayfish (Raja clavata) weighing around 0.5 and $1.3 \mathrm{~kg}$, respectively, were caught in the Bay of Concarneau and kept in running-seawater tanks at $15^{\circ} \mathrm{C}$ for at least 7 days prior to experiments. Once a week, they were on a diet of squid and fish flesh. Our investigations were conducted only on fish obviously in good condition.

\section{Histology}

The metabolic characteristics of muscle fibers can be displayed through the use of histochemical staining techniques (Dubowitz et al., 1985).

The fish were anesthetized with tricaine methane sulfate (MS 222), killed by decapitation and descaled. Tissue blocks, 3-4-cm in length, containing red, intermediate and white muscles were dissected on a 4-cm layer from the median part of the trunk (squales) and the fin (skates). The samples were oriented so that the muscle fibres were cut 
at right angles to their long axis.

For study of fibres-direction and -type, the pieces oriented longitudinally or transversally were fixed in Bouin's fluid for $24-48 \mathrm{~h}$ at $4^{\circ} \mathrm{C}$, then dehydrated through ascending ethanol series and embedded in paraffin wax. Sections were then colored with hematein-eosin.

For histochemical study, the tissue was rapidly frozen in isopentane cooled to its freezing point with liquid nitrogen $\left(-160^{\circ} \mathrm{C}\right)$, and then sectioned in a cryostat at $-25^{\circ} \mathrm{C}$. Longitudinal and transversal sections $(5 \mu \mathrm{m})$ were mounted on glass slides, air-dried at room temperature and stained for glycogen with the periodic-acid schiff reagent (PAS) (Pearse, 1968), and for lipids using Sudan Black (Chiffelle and Putt, 1951).

Ten- $\mu \mathrm{m}$-thick transverse sections were cut and mounted on glass slides and then stained to evidence the following enzymes:

- NADH Tetrazolium Reductase (NADH-TR, EC 1.6.99.3): this enzyme is used for evaluation of the oxidative capacity of fibre types (Nachlas et al., 1958). The incubation medium contained $10 \mathrm{ml} 0.2 \mathrm{M}$ Tris/ $\mathrm{HCl}$ buffer $(\mathrm{pH} 7.4), 10 \mathrm{ml}$ of $2.4 \mathrm{mM}$ nitro-blue tetrazolium and $0.27 \mathrm{mM}$ NADH. Incubation at $37^{\circ} \mathrm{C}$ took $20-30 \mathrm{~min}$.

- succinic dehydrogenase (SDH, EC 1.3.99.1): this mitochondrial enzyme is used to separate oxidative from anaerobic fibres (Nachlas et al., 1957). The incubation medium was made of $10 \mathrm{ml}$ of $0.2 \mathrm{M}$ potassium phosphate buffer ( $\mathrm{pH} 7.4), 10 \mathrm{ml}$ of $2.4 \mathrm{mM}$ nitroblue tetrazolium, and $100 \mathrm{mM} \mathrm{Na}$-succinate. The incubation lasted $2 \mathrm{~h}$ at $37^{\circ} \mathrm{C}$.

- Menadione-linked a-glycerophosphate deshydrogenase (M $\alpha-\mathrm{GPDH}, \quad \mathrm{EC}$ 1.1.99.5): used as a measure of aerobic metabolic capacities (Wattenberg and Leong, 1960). This enzyme is an intramitochondrial flavoprotein. The enzyme activity can be 
increased by vitamin $\mathrm{K}_{3}$ (menadione), which acts as a hydrogen acceptor. The incubation medium consisted of $10 \mathrm{ml} 0.2 \mathrm{M}$ Tris/ $\mathrm{HCl}$ buffer ( $\mathrm{pH} 7.4$ ), $10 \mathrm{ml}$ of $2.4 \mathrm{mM}$ nitro-blue tetrazolium, $\alpha$-glycerophosphate $\left(3 \mathrm{mg} \cdot \mathrm{ml}^{-1}\right)$, and $0.01 \%$ menadione. Samples were incubated at $37^{\circ} \mathrm{C}$ for $20-30 \mathrm{~min}$.

- Phosphorylase (EC 2.4.1.1): The incubation medium consisted of $5 \mathrm{ml}$ of $0.2 \mathrm{M}$ $\mathrm{Na}$ acetate buffer ( $\mathrm{pH} 5.6-6.0), 2 \mathrm{ml}$ of absolute ethanol, $5 \mathrm{ml}$ of bidistilled water with $25 \mathrm{mg}$ of glucose-1-phosphate, 1.2 M adenosine-5'-monophosphate (AMP) and $5 \mathrm{mg}$ of glycogen. Samples were incubated for $1 \mathrm{~h}$ at $37^{\circ} \mathrm{C}$ and then stained with Lugol $(10 \%)$ (Swanson, 1948).

- AMP-deaminase: as described in Fishbein et al. (1980): The incubation medium contained $0.7 \mathrm{ml} 3 \mathrm{M} \mathrm{KCl}, 1.2 \mathrm{M}$ AMP, $2.4 \mathrm{mM}$ nitro-blue tetrazolium, and $0.1 \mathrm{mM}$ dithiothreitol, at $\mathrm{pH}$ 6.1. The incubation lasted for $1 \mathrm{~h}$ at $20^{\circ} \mathrm{C}$. Positive controls for staining consisted of tissue sections from human skeletal muscle. Substrate-free controls were also prepared for all the reactions, except for the PAS stain where the oxidation by periodic acid was omitted. In each case, negative result was obtained, and thus confirmed the reaction specificity.

\section{Assay of AMP-deaminase activity}

Pieces from axial muscle and from fin muscle were rapidly dissected from squales and skates, respectively.

A $10 \%(\mathrm{w} / \mathrm{v})$ suspension was made in $0.089 \mathrm{M}$ potassium phosphate (pH 6.5), $0.18 \mathrm{M}$ $\mathrm{KCl}, \quad 0.1 \mathrm{mM}$ dithiothreitol. The tissue was homogeneized in an Ultra-Turrax homogeneizer for $2 \times 20 \mathrm{~s}$, with intermediate cooling in ice. Then the extract was diluted 
in the same volume of homogeneization buffer, gently stirred for $1 \mathrm{~h}$ at room temperature and used for determination of enzyme activity without prior centrifugation.

The chromatographic method previously reported by Raffin and Thébault (1991) was used to determine AMP-deaminase activity through assessment of IMP produced from AMP. A solution of cacodylate buffer (50 mM, pH 6.5) was made as previously described (Raffin et al. 1993b). The AMP concentration was $10 \mathrm{mM}$ and the incubation temperature was $26^{\circ} \mathrm{C}$ for all the fish and $37^{\circ} \mathrm{C}$ for the rat. One unit of AMP-deaminase activity corresponds to the amount of enzyme that deaminates $1 \mu$ mole of substrate $\min ^{-1}$ under our experimental conditions; activity is expressed as $\mathrm{U} \mathrm{g}^{-1}$ wet weight). 


\section{RESULTS}

\section{AMP-deaminase activity in different fish species}

Steady activity difference between fish species could be measured in the white muscle (Table 1). The level of activity in the cyclostom Petromyzon marinus and the teleost Oncorhynchus mykiss white muscles was similar to that of the mammals. Among the chondrosteans, those belonging to the families of Chimaeridae, Rajidae, Squalidae, Torpinidae, and Triakidae displayed an AMP-deaminase activity similar to that of the mammals in their white muscles, whereas the activity was significantly lower in Hexanchidae and Scyliorhinidae.

In order tofind out if the AMP-deaminase followed the same pattern in red muscle, the activity of the enzyme from red muscle was compared to that of white muscle, in two representative elasmobranch species, Raja clavata and Scyliorhinus canicula (Table 2). In the dogfish, the AMP-deaminase activity was sixfold lower in the red muscle than in the white muscle. Also, in the rayfish, the activity tended to be lower in the red muscle, but the difference was not significant.

\section{Histological studies and AMP-deaminase assays in rayfish and dogfish}

Histological studies and enzyme assays were performed in two elasmobranch species, Raja clavata and Scyliorhinus canicula.

\section{Muscle fibres orientation and type}

In $S$. canicula, the fibres-containing compartments are about 2.5-mm-long and 
parallelly aligned from head to tail. The muscle fibres are longitudinally directed. On the contrary in $R$. clavata, the muscle fibers are at right angle to the vertebrate chord and radiate towards the fin. In transversal sections, size and histo-enzymology reactions allowed us to classify the muscle fibres into three groups, white (W), red (R) and intermediate (I).

Figure 1 clearly shows the three types of fibres identified in the dogfish lateral muscle as well as portions of the myotomal musculature at the anterior end of the body. Just underneath the skin, a 1-mm-thin cortical zone of about 15 layers contains the NADH-TR-positive red fibres running almost parallel to the long axis of the body; these small-size fibres (67 $\mu \mathrm{m}$ in diameter) contain a dark colored cytoplasm and peripheral nuclei.

Near the vertebral axis, a larger zone containing almost all the cones (95\%) is composed of large NADH-TR-negative fibres (155 $\mu \mathrm{m}$ in diameter) tilted towards the long axis; some partially internalized nuclei are visible. Their cytoplasm was weakly stained.

Adjacent to the white muscle, a thin zone of fibres $(117-\mu \mathrm{m}$ in diameter), with partially internalized nuclei, was moderately stained after standard and NADH-TR staining reactions.

Table 3 illustrates the data obtained by histo-enzymology on the localization of glycogen, lipids, NADH-TR, menadione-linked $\alpha$-glycerophosphate dehydrogenase and phosphorylase. None of the fibres, whatever their type, were stained with Sudan Black. The red and intermediary fibres were fairly stained with PAS, whereas the white ones displayed a milder coloration. NADH-TR activity was found essentially in the red muscle fibres. The intermediate fibres were moderately stained, whereas the white ones showed very mild coloration. 
Figure 2 illustrates the characteristics of the rayfish fin muscle. The red-fibre zone under the skin is thicker than in the dogfish muscle $(2-2.5 \mathrm{~mm})$ and larger underneath the animal. The mean diameter of the cells is $50 \mu \mathrm{m}$. The white-fibre zone accounts for $95 \%$ of the cones with cells of $180-\mu \mathrm{m}$ in mean diameter. The intermediate fibres consist of $115-\mu \mathrm{m}$-mean-diameter cells. Some of them display a mosaic distribution within the white fibres, while others form an intermediary layer like in dogfish. The histochemical characteristics of muscle fibres were similar to those of the dogfish (Table 3).

\section{Stain for AMP-deaminase}

The AMP-deaminase staining of the dogfish and rayfish myotomes produced similar results with no staining of the red fibres (Figures 3 a and c). As for the white fibres, in dogfish they exhibited a blue reticular staining on a diffusely pink-colored cytoplasm. On the other hand, in rayfish they were heavily stained with a high degree of granularity (Figures $3 \mathrm{~b}$ and $\mathrm{d}$ ). 


\section{DISCUSSION}

The concentration of AMP-deaminase found in skeletal muscle of mammals is considerably higher than in other mammalian tissues (Ogasawara et al. 1983), and than in invertebrate white muscle (Raffin and Thébault 1987). Our results show that a significant increase of the AMP-deaminase activity took place in the elasmobranch group. Then, the enzyme activation was a several-step mechanism which occured during the appearance of vertebrates. Amplification of AMP-deaminase activity could be related to the extensive events that occurred, simultaneous to the gene duplication, at the very beginning of vertebrate evolution (Ohno et al. 1969).

Molecular studies have demonstrated that mammalian AMP-deaminases are made manifest through the expression of a multigene family. Previous molecular studies have reported two genes, $A M P D 1$ and $A M P D 2$, that produce isoform $\mathrm{M}$ and $\mathrm{L}$ transcripts, respectively (Morisaki et al. 1990). AMPD1 is expressed at high levels in adult skeletal muscle, while the $A M P D 2$ transcript is detected primarily in adult nonskeletal muscle tissues and embryos (Sabina et al. 1989, Morisaki et al. 1990). A third AMP-deaminase gene has been identified in human, $A M P D 3$, encoding transcripts that are specific for the E isoforms in erythrocytes (Mahnke-Zizelman and Sabina 1992). Detailed studies on AMP-deaminase in white muscle from Schyliorhinus canicula and Raja clavata showed that the difference in the enzyme activity found between the two species was correlated with the appearance, in Rajidae, of an enzymatic form very close to the $A M P D 1$ gene product of higher vertebrates (Raffin et al. 1993 a). Thus, in this animal group, the AMPdeaminase activity difference of 3-4 fold could indicate a genetic modification of the AMP-deaminase molecule. 
Very little information has been available on AMP-deaminase isozymes from red muscle. Our study shows that, in Scyliorhinus canicula, the AMP-deaminase activity was much lower in red fibres than in white fibres, as in mammals (Ogasawara et al. 1978). In Raja clavata, a non significant difference between the activities of red and white fibres could result from the difficulty to separate the different types of fibres in the fins of skates, as shown by high values of the standard deviation. In mammals, two different isozymes exist in red muscle; one is identical to the isozyme in heart (isoform L), and the other of the isozyme in white muscle (isoform M) (Raggi et al. 1979, Ogasawara et al. 1983). To our knowledge, nothing is known about the isozyme pattern in fish red and white muscles.

Rayfish and dogfish are benthic fish that live at depths from 20 to $400 \mathrm{~m}$. But, both species differ in the way they swim. The dogfish swimming is based on undulatory sidemovements of the trunk and tail resulting from contractions of axial muscles. Active swimming to escape a predator is achieved through vigorous contractions of the axial muscle fibres. The rayfish moves at low speed by undulatory vertical movements of the large pectoral fins; its caudal muscles contract noticeably, but only during vigorous bursts of activity.

Histochemistry has been acknowledged as a valuable tool in investigations into muscle tissues in lower vertebrates (Johnston et al. 1975, Mellgren and Mathisen 1966). The fin muscle fibres of the rayfish are differenciated in three distinct types: red, intermediate and white, like in dogfish and other elasmobranch species (Bone 1966, Bone and Chubb 1978, Kryvi and Totland 1978, Johnston 1981); the intermediate and white fibres show great similarities in their respective morphology. However, the way they are arranged in the rayfish differs from that of the dogfish: the red-fibre zone is thicker, particularly in the superior part of the fin. Near the vertebrate chord, the muscular mass 
consists mainly of white fibres; on the other hand, even though the intermediate fibres are mostly found between the red and white ones where they form a strip, some of them, which account for $5 \%$ of the total fibres, are dispersed between the white fibres. This layout is similar to one found in some teleost fish (Johnston et al. 1977, Chayen et al. 1987).

In fish, the recruitment of the different types of fibres with respect to the swimming speed has been thoroughly investigated, and is known to depend on the motor system innervation (Johnston 1981). In dogfish, each white fibre is innervated by two separate axons which fuse to form a single end-plate (Bone 1964, 1972). In such innervation systems, only the red fibres are implicated in slow swimming, whereas the white ones become active for fast and vigorous movements (Bone 1966, Johnston 1981). In multiple innervated systems, several studies have highlighted that, at sustainable swimming speeds in some species, the white and red fibres are both recruited (Hudson 1973, Davison and Goldspink 1977, Johnston et al. 1977, Bone et al. 1978, Johnston and Moon 1980) whereas, in other species, they are recruited in more primitive pattern (Freadman 1979). In the white fibres of Torpedo, the more superficial ones have a basket-like end plate, like those of the dogfish (Bone 1964). However, to our knowledge, neither the innervation system of rayfish fin muscles, nor its fibre recruitment as a function of speed has been investigated. A peculiarity of the rayfish myotome is the dispersion of intermediate fibres among the white ones. According to some authors the intermediate fibres would be associated with the fish ability to swim continuously for a long time (Bokdawala 1967, Patterson et al. 1975), but this assumption is still questioned.

Though our histo-enzymology-based study failed to evidence differences between rayfish and dogfish in the activities of the mitochondrial marker enzymes (SDH, NADH- 
TR), phosphorylase and M $\alpha$-GPD enzymes, a marked difference was observed for AMPdeaminase in white fibres. These experimental data, together with the AMP-deaminase assays in the white and red fibres of both species, corroborated the information ona higher activity in the rayfish fin muscles. As observed in mammals, their white fibres contained more AMP-deaminase than the red ones. Further, molecular studies will have to be carried out to determine if this is related to, either a modification of the enzyme structure, or a higher expression rate of the corresponding gene. Indeed, the high AMP-deaminase activity in rayfish white fibres could be correlated to the increase in muscle complexity.

Fibre typing in AMP-deaminase staining is more based on difference in color rather than in intensity. Because of the lack of inherent relation between the color differentiation and the enzyme reaction, the intensity of the pink color and the degree of blue granularity may depend on the amount of cytoplasmic enzyme and that of the enzyme bound to mitochondria and sarcoplasmic reticulum in the intermyofibrillar network, respectively (Fishbein et al. 1980). In mammals, type-II fibres show a diffuse pink staining, whereas type-I fibers display a granular blue staining. The slight stain obtained for the dogfish white fibres may result from their low content in enzyme as confirmed by the low activity found in solution assays.

Prior studies have demonstrated that, in mammalian muscle, AMPD1 binds to the S-2 fragment of myosin, and that complex formation makes the reaction less susceptible to inhibition by GTP (Ashby and Frieden, 1977, 1978; Ashby, Frieden and Bishoff, 1979). Binding to the myofibril varies with the state of muscle contraction in vivo and is required for activation of the enzyme in myocytes (Hisatome et al., 1998). As the experiments of Lushchak and Storey (1994) and Lushchak et al. (1998) on teleost muscle show clearly that enzyme binding to the particulate fraction of muscle increases in exercising skeletal 
muscle and in muscle of fish exposed to hypoxia, it is very likely that the control of AMPdeaminase by the combined effects of allosteric modifiers and enzyme interactions with cellular structural elements has a more general character. However, the association of AMP-deaminase to particular fraction of muscle in elasmobranch fish displaying a low AMP-deaminase activity has been investigated. So a possible regulation by binding to cellular structure elements cannot be proposed in these fish.

In conclusion, this study shows that transition from ancestral to evolved AMPdeaminase forms has occurred in at least two taxa: the one that evolved to rajiform elasmobranch fish and the other to the land vertebrates. An important point is that the enzyme activation and appearance of a molecular form similar to the mammal AMPdeaminase occurred within the phylogenic evolution of the major fish groups. Finally, our comparative study of two elasmobranches suggests that enhancement of AMP-deaminase activity goes along with a higher complexity of the muscular structure as evidenced by the rudimentary mosaïc arrangement between red and white fibres.

\section{ACKNOWLEDGEMENTS}

We thank Dr. Joël Querellou for access to HPLC equipement at Ifremer. 


\section{REFERENCES}

Ashby, B., Frieden, C. 1977. Interaction of AMP-aminohydrolase with myosin and its subfragments. J. Biol. Chem. 252, 1869-1872.

Ashby, B., Frieden, C., Bishoff, R. 1979. Immunofluorescent and histochemical localization of AMP-deaminase in skeletal muscle. J. Cell Biology 81, 361-373.

Ashby, B., Frieden, C. 1978. Adenylate deaminase. Kinetic and binding studies on the rabbit muscle enzyme. J. Biol. Chem. 253, 8728-8735.

Bokdawala, F.D. 1967. A histochemical study of fat in the red and white muscle fibres of fin skeletal muscle. J. Anim. Morphol. Physiol. 14, 231-241.

Bone, Q. 1964. Patterns of muscular innervation in the lower chordates. Int. Rev. Neurobiol. 6, 99-147.

Bone, Q. 1966. On the function of the two types of myotomal muscle fibres in elasmobranch fish. J. Mar. Biol. Ass. UK. 46, 321-349.

Bone, Q. 1972. The dogfish neuromuscular junction: Dual innervation of vertebrate striated muscle fibres? J. Cell. Sci. 10, 657-665.

Bone, Q., Chubb, A.D. 1978. The histochemical demonstration of myofibrillar ATPase in elasmobranch muscle. Histochem. 10, 489-494.

Bone, Q., Kicnuik, J., Jones, D.R. 1978. On the role of the different fibre types in fish myotomes at intermediate swimming speeds. Fish. Bull. USA. 76, 691-699.

Broberg, S., Sahlin, K. 1989. Adenine nucleotide degradation in human skeletal muscle during prolonged exercise. J. Appl. Physiol. 67, 116-122.

Burke, R.E., Levine, D.N., Zajac, F.E., Tsairis, P., Engel, W.K. 1971. Mammalian 
motor units: physiological-histochemical correlation in three types in cat gastrocnemius. Science 174, 709-712.

Chapman, A.G., Atkinson, D.E. 1973. Stabilization of adenylate energy charge by the AMP-deaminase reaction. J. Biol. Chem. 248, 8309-8312.

Chayen, N., Freundlich, A., Squire, J.M. 1987. Comparative histochemistry of a flatfish fin muscle and of other vertebrate muscles used for ultrastructural studies. J .Muscle Res. Cell. Motil. 4, 358-371.

Chiffelle, T.L., Putt, F.A. 1951. Propylene and ethylene glycol as solvents for Sudan IV and Sudan Black B. Stain Technol. 26, 51-56.

Davison, W,. Goldspink ,G. 1977. The effect of prolonged exercise on the lateral musculature of the brown trout (Salmo trutta). J. Exp. Biol. 70, 1-12.

Dubowitz, V., Sewry, C.A., Fitzsimons, R.B. 1985. Histological and histochemical stains and reactions. In: Saunders, W.B. (Ed.), Muscle biopsy, a practical approach, $2^{\text {nd }}$ edn, Baillière Tindall, London, pp. 19-40.

Fishbein, W.N., Griffin, J.L., Nagarajan, K. 1979. Immunologic uniqueness of muscle adenylate deaminase and genetic transmission of the deficiency state. Clin. Res. $27,274 \mathrm{~A}$.

Fishbein, W.N., Griffin, J.L., Armbrustmacher, V.W. 1980. Stain for skeletal muscle adenylate deaminase. Arch. Pathol. Lab. Med. 104, 462-46.

Freadman, M.A. 1979. Role of partitioning of swimming musculature of striped bass, Morone saxatilis Walbaum and Bluefish, Pomatomus saltatrix L. J. Fish Biol. 15, 417-423.

Hisatome, I., Morisaki, T., Kamma, H., Sugama, T., Morisaki, H., Ohtahara, A., 
Holmes, E.W. 1998. Control of AMP deaminase 1 binding to myosin heavy chain. Am. J. Physiol. 275, C870-C881.

Hudson, R.C.L. 1973. On the function of the white muscles in teleosts at intermediate swimming speeds. J. Exp. Biol. 58, 509-522.

Johnston, I.A., Ward, P.S., Goldspink, G. 1975. Studies on the swimming musculature of the rainbow trout. I. Fibre types. J. Fish Biol. 7, 451-458.

Johnston, I.A., Davison, W., Goldspink, G. 1977. Energy metabolism of carp swimming muscle. J. Comp. Physiol. 114 B, 203-216.

Johnston, I.A., Moon, T.W. 1980. Endurance exercise training in the fast and low muscles of a teleost fish (Pollachius virens) $)$ J. Comp. Physiol. 135 B, 147-156.

Johnston, I.A. 1981. Structure and function of fish muscles. Symp. Zool. Soc. Lond. 48, 71-113.

Kaletha, K., Thébault, M.T., Raffin, J.P. 1991. Comparative studies on heart and skeletal muscle AMP-deaminase from rainbow trout ( $\underline{\text { Salmo gairdneri) }}$. Comp. Biochem. Physiol. 99 B, 751-754.

Krivy, H., Totland, G.K. 1978. Fibre types in locomotory muscles of the cartilagenous fish Chimaera monstrosa. J. Fish Biol. 12, 257-265.

Lannergreen, J., Hoh, J.F.K. 1984. Myosin isoenzymes in single muscle fibres of Xenopus laevis: analysis of five different functional types. Proc. Roy. Soc. Lond. Ser. 222 B, 401-408.

Lowenstein, J.M. 1972. Ammonia production in muscle and other tissues. The purine nucleotide cycle. Physiol. Rev. 52, 382-414.

Lushchak, V.I., Storey, K.B. 1994. Influence of exercise on the distribution of enzymes 
in trout white muscle and kinetic properties of AMP-deaminase from free and bound fractions. Fish Physiol. Biochem. 13, 407-418.

Lushchak, V.I., Smirnova, Y.D., Storey, K.B. 1998. AMP-deaminase from sea-scorpion white muscle: properties and redistribution under hypoxia. Comp. Biochem. Physiol., 119 B, 611-618.

Mahnke-Zizelman, D.K., Sabina, R.L. 1992. Cloning of human AMP-deaminase isoform EcDNAs. Evidence for a third AMPD gene exhibiting alternatively spliced 5'-exons. J. Biol. Chem. 267, 20866-20877.

Mellgren, S.I., Mathisen, J.S. 1966. Oxidative enzymes, glycogen and lipid in striated muscle. A histochemical study in the atlantic hagfish [Myxine glutinosa (L)]. Z. Zellforsh Mikrosk. Anat. 71, 169-188.

Meyer, R.A., Terjung, R.L. 1980. AMP deamination and IMP reamination in working skeletal muscle. Am. J. Physiol. 239, C32-C38, 1980.

Morisaki, T., Sabina, R., Holmes, E.W. 1990. Adenylate deaminase. A multigene family in humans and rats. J. Biol. Chem. 265, 11482-11486.

Nachlas, N.M., Tsou, K.G., DeCheng, C.S., Seligman, A.M. 1957. Cytochemical demonstration of succinic dehydrogenase by the use of a new p-nitrophenyl substituted ditetrazole. J. Histochem. Cytochem. 5, 420-436.

Nachlas, N.M., Walker, D.G., Seligman, A.M. 1958. A histochemical method for the demonstration of diphosphopyridine nucleotide diaphorase. J. Biophys. Biochem. Cytol. 4, 29-38.

Ogasawara, N., Yoshino, M., Kawamura, Y. 1972. Multiple forms of AMP-deaminase in rat brain. Biochim. Biophys. Acta 258, 680-684. 
Ogasawara, N., Goto, H., Watanabe, T. 1975. Isozymes of rat AMP-deaminase. Biochim. Biophys. Acta 403, 530-537.

Ogasawara, N., Goto, H., Yamada, Y., Watanabe, T. 1978. Distribution of AMPdeaminase isozymes in rat tissues. Eur. J. Biochem. 87, 297-304.

Ogasawara, N., Goto, H., Yamada, Y. 1983. AMP-deaminase isozymes in rabbit red and white muscles and heart. Comp. Biochem. Physiol. 76 B, 471-473.

Ohno, S., Muramoto, J., Stenius, C., Christian, L., Kittrell, W.A., Atkin, N.B. 1969. Microchromosomes in Holocephalian, Chondrostean and Holostean fishes. Chromosoma (Berl.) 26, 35-40.

Patterson, S., Johnston, I.A., Goldspink, G. 1975. A histochemical study of the lateral muscles of five teleosts species. J. Fish Biol. 7, 159-166.

Pearse, A.G.E. 1968. Histochemistry. Theoretical and Applied, $3^{\text {rd }}$ edn Vol.1.. J.\& A. Churchill Ltd., London, 759 pp.

Purzycka, J. 1962. AMP and adenosine aminohydrolases in rat tissues. Acta Biochim. Pol. 9, 83-93.

Raffin, J.P., Leray, C. 1980. Comparative study on AMP-deaminase in gill, muscle and blood of fish. Comp. Biochem. Physiol. 67 B, 533-540.

Raffin, J.P., Thébault, M.T. 1987. Purification and partial characterization of an AMPdeaminase from the marine invertebrate Palaemon serratus. Comp. Biochem. Physiol. 88 B, 1071-1076.

Raffin, J.P., Thébault, M.T. 1991. A specific AMP-deaminase assay and its application to tissues homogenates. Comp. Biochem. Physiol. 99 B, 125-127.

Raffin, J.P., Thébault, M.T., Izem, L. 1993a. The genetic amplification of muscular 
AMP-deaminase: Towards the identification of evolutionary steps. Trends Comp. Biochem. Physiol. 1 B, 171-181.

Raffin, J.P., Izem, L., Thébault, M.T. 1993b. Amplification of myoadenylate deaminase during evolution. 2. Purification and properties of the enzyme from two elasmobranch fishes, Scyliorhinus canicula and Raja clavata. Comp. Biochem. Physiol. 106 B, 999-1007.

Raggi, A., Ronca-Testoni, S., Ronca, G. 1969. Muscle AMP aminohydrolase: II. Distribution of AMP aminohydrolase, myokinase and creatine kinase activities in skeletal muscle. Biochim. Biophys. Acta 178, 619-622.

Raggi, A., Bergamini, C., Ronca, G. 1979. Isozymes of AMP-deaminase in red and white muscle. FEBS Lett. 56, 19-23.

Rowlerson, A., Spurway, Y.N. 1985. How many fibre types in amphibian limb muscles? A comparison of Rana and Xenopus. J. Physiol. 358, 78P.

Sabina, R., Ogasawara, N., Holmes, E.W. 1989. Expression of three stage-specific transcripts of AMP-deaminase during myogenesis. Mol. Cell. Biol. 9, 22442246.

Swanson, M.A. 1948. Studies on the structure of polysaccharides. IV. Relation of the iodine colour to the structure. J. Biol. Chem. 172, 825-837.

Van Waarde, A., Kesbeke, F. 1981. Regulatory properties of AMP-deaminase from lateral red muscle and dorsal white muscle of goldfish, Carassius auratus (L). Comp. Biochem. Physiol. 69B, 413-423.

Van Waarde, A. 1988. Operation of the purine nucleotide cycle in animal tissues. Biol .Rev. 63, 259-298. 
Veech, R.L., Lawson, J.W.R., Cornell, N.W., Krebs, H.A. 1979. Cytosolic phosphorylation potential. .J Biol. Chem. 254, 6358-6547.

Wattenberg, L.W., Leong, J.L. 1960. Effects of coenzyme Q10 and menadione on succinic dehydrogenase activity as measured by tetrazolium salt reduction. J. Histochem. Cytochem. 8, 296-303. 


\section{CAPTIONS TO FIGURES}

Fig. 1: Transverse section of axial muscle of the dogfish.

a: hematein-eosin stain ; b: NADH-TR stain.

White fibres (W); Red fibres (R); Intermediate fibres (P)

Bar represents $100 \mu \mathrm{m}$.

Fig. 2: Transverse sections of axial muscle of the rayfish.

a: hematein-eosin stain ; b: NADH-TR stain.

White fibres (W); Red fibres (R); Intermediate fibres (P).

Bar represents $100 \mu \mathrm{m}$.

Fig. 3: AMP-deaminase histochemistry.

AMP-deaminase activity was assayed in transverse sections of dogfish and rayfish axial muscles.

a: dogfish red fibres ; b: dogfish white fibres ; c: rayfish red fibres ; d: rayfish white fibres. Bar represents $100 \mu \mathrm{m}$. 
Table 1. Determination of AMP-deaminase activity in white muscle of different fish species, compared with mammals

\begin{tabular}{|ll|c|c|}
\hline & Species & Type of muscle & Activity (U/g FW) \\
\hline Cyclostoms & Petromyzon marinus (6) & White muscle (median part of the trunk) & $44.1 \pm 14.0$ \\
Chimaeridae & Chimaera monstrosa (4) & White muscle (median part of the trunk) & $202 \pm 162$ \\
Hexanchidae & Hexanchus griseus (1) & White muscle (median part of the trunk) & 40.6 \\
Scyliorhinidae & Scyliorhinus canicula (6) & White muscle (median part of the trunk) & $19.3 \pm 3.24$ \\
& Galeus melastomus (6) & White muscle (median part of the trunk) & $72.6 \pm 29.9$ \\
Triakidae & Galeorhinus galeus (5) & White muscle (median part of the trunk) & $116 \pm 58.9$ \\
Squalidae & Etmopterus spinax (6) & White muscle (fin) & $108 \pm 31.2$ \\
& Squalus acanthias (6) & White muscle (fin) & $177 \pm 69.8$ \\
Torpenidae & Torpedo marmorata (5) & White muscle (fin) & $163 \pm 32.7$ \\
Rajidae & Raja circularis (6) & White muscle (fin) & $259 \pm 134$ \\
& Raja clavata (6) & White muscle (fin) & $247 \pm 103$ \\
& Raja fullonica (4) & White muscle (fin) & $288 \pm 54.9$ \\
& Raja montagui (6) & White muscle (fin) & $323 \pm 88.6$ \\
& Raja naevus (6) & White muscle (fin) & $173 \pm 78.6$ \\
Salmonidae & Oncorhynchus mykiss (5) & White muscle (median part of the trunk) & $139 \pm 10.4$ \\
Mammal & Rat (Wistar) (6) & Fast lateral gastrocnemius & $153 \pm 46.6$
\end{tabular}

n: number of specimen

AMP-deaminase activity is expressed as Units/g of wet weight. One enzyme activity unit was defined as the amount of enzyme that catalyzes the formation of $1 \mu \mathrm{mol}$ of IMP per min at $10 \mathrm{mM}$ substrate concentration and $26^{\circ} \mathrm{C}$. 
Table 2. AMP-deaminase activity in dogfish and rayfish myotome extracts.

\begin{tabular}{|c|c|c|}
\hline Enzyme origin & $\begin{array}{c}\text { Activity in red fibres } \\
\text { (U/g FW) }\end{array}$ & $\begin{array}{c}\text { Activity in white fibres } \\
\text { (U/g FW) }\end{array}$ \\
\hline Scyliorhinus canicula & $3.19 \pm 1.89$ & $19.30 \pm 3.24^{*}$ \\
\hline Raja clavata & $162 \pm 14.5^{\circ}$ & $247 \pm 103^{\circ}$ \\
\hline
\end{tabular}

One enzyme activity unit was defined as the amount of enzyme that catalyzes the formation of $1 \mu \mathrm{mol}$ of IMP per min at $10 \mathrm{mM}$ substrate concentration and $25^{\circ} \mathrm{C}$.

Data are mean \pm SD from 6 measurements.

Significant differences between red and white fibres: $*(p \leq 0.001)$

Significant differences between dogfish and rayfish: ${ }^{\circ}(p \leq 0.001)$ 
Table 3. Summary of the histo-enzymologic study of myotomal muscles from the dogfish (Scyliorhinus canicula) and the rayfish (Raja clavata), compared to human.

\begin{tabular}{|c|c|c|c|c|c|c|c|c|c|c|c|c|c|c|c|c|c|c|c|c|c|}
\hline Tissue & \multicolumn{3}{|c|}{ NADH-TR } & \multicolumn{3}{|c|}{$\mathrm{SDH}$} & \multicolumn{3}{|c|}{$M \alpha-G P D$} & \multicolumn{3}{|c|}{ Phyla } & \multicolumn{3}{|c|}{ PAS } & \multicolumn{3}{|c|}{ Sudan Black } & \multicolumn{3}{|c|}{ AMPdase } \\
\hline & $\mathrm{S}$ & $\mathrm{R}$ & $\mathrm{H}$ & $\mathrm{S}$ & $\mathrm{R}$ & $\mathrm{H}$ & $\mathrm{S}$ & $\mathrm{R}$ & $\mathrm{H}$ & $\mathrm{S}$ & $\mathrm{R}$ & $\mathrm{H}$ & $\mathrm{S}$ & $\mathrm{R}$ & $\mathrm{H}$ & $\mathrm{S}$ & $\mathrm{R}$ & $\mathrm{H}$ & $\mathrm{S}$ & $\mathrm{R}$ & $\mathrm{H}$ \\
\hline Red fibres & +++ & +++ & +++ & +++ & +++ & +++ & $-/+$ & $+/-$ & + & + & & + & ++ & +++ & + & - & - & ++ & - & - & + \\
\hline Intermediate & ++ & ++ & ++ & + & + & + & ++ & ++ & ++ & ++ & & ++ & ++ & ++ & ++ & - & - & $+/-$ & + & +++ & ++ \\
\hline White fibres & + & + & + & + & ++ & & ++ & ++ & +++ & $++^{\circ}$ & ++ & +++ & + & + & +++ & - & - & $+/-$ & + & +++ & ++ \\
\hline
\end{tabular}

\section{S: Scyliorhinus canicula; R: Raja clavata; H: Human}

NADH-TR: NADH Tetrazolium Reductase; SDH: Succinic Dehydrogenase; M $\alpha$-GPD: Menadione-linked $\alpha$ - glycerophosphate dehydrogenase; Phyla: Phosphorylase; PAS: periodic acid schiff reagent; AMPdase: AMP-deaminase.

+++: heavily stained; ++: fairly stained; +: very lightly stained; -: no staining. 
a

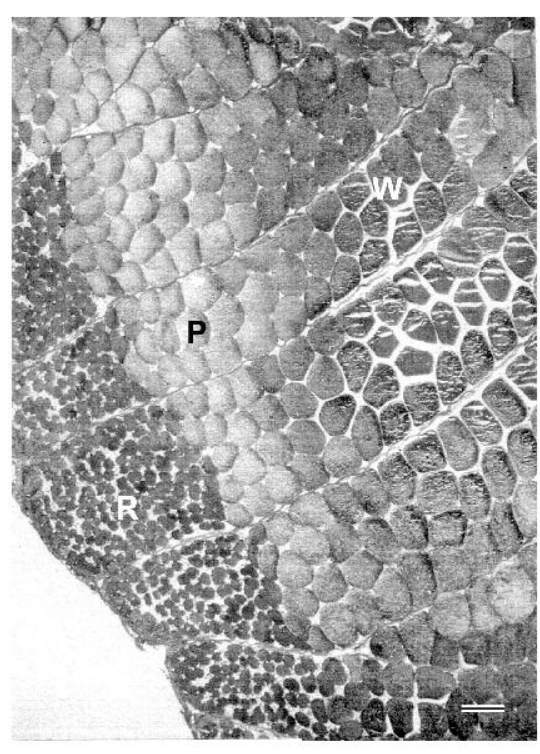

b

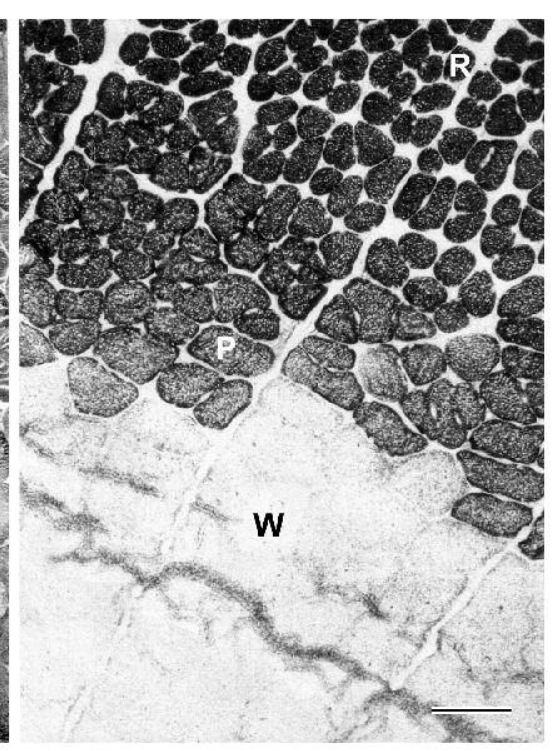

Fig.1 
a
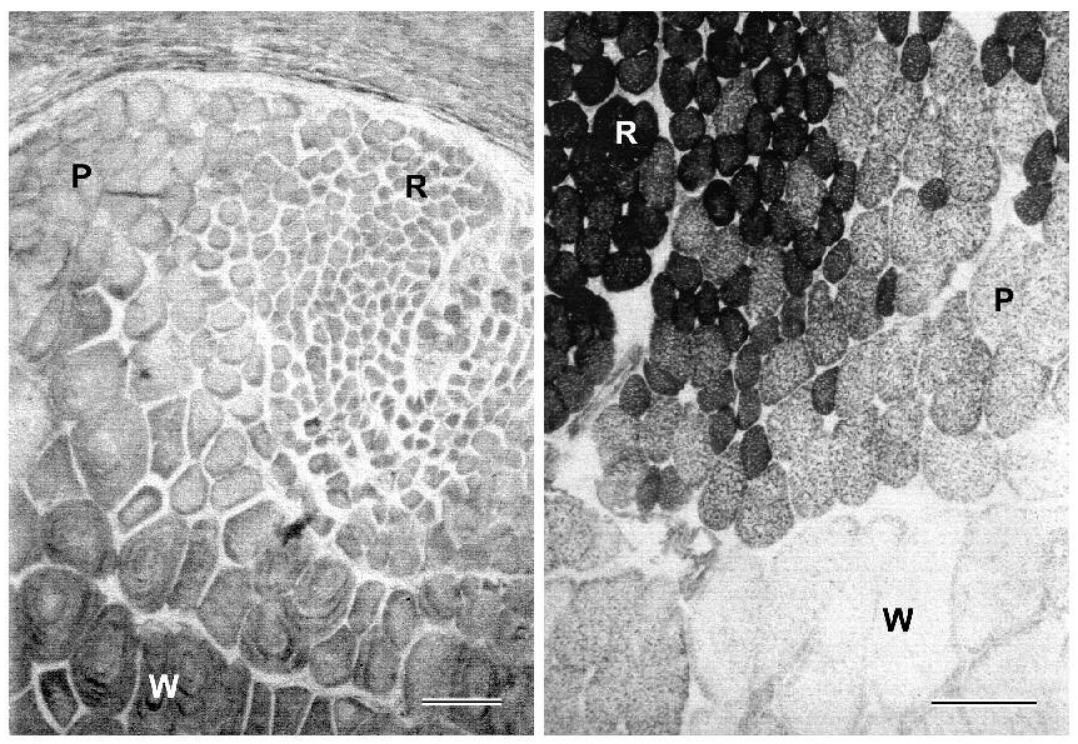

Fig.2 b

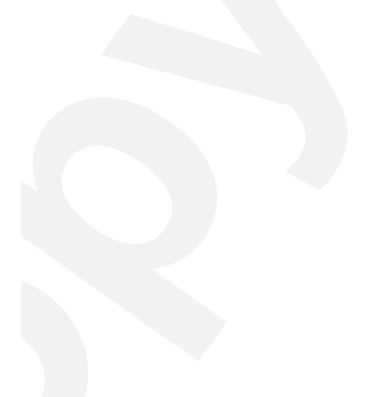


a

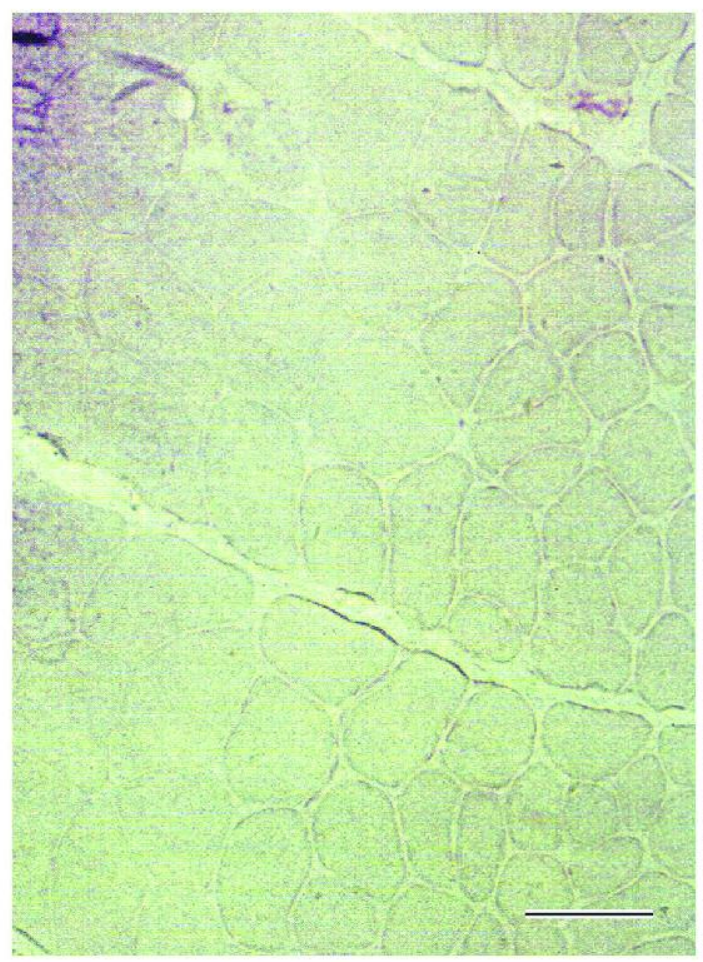

c

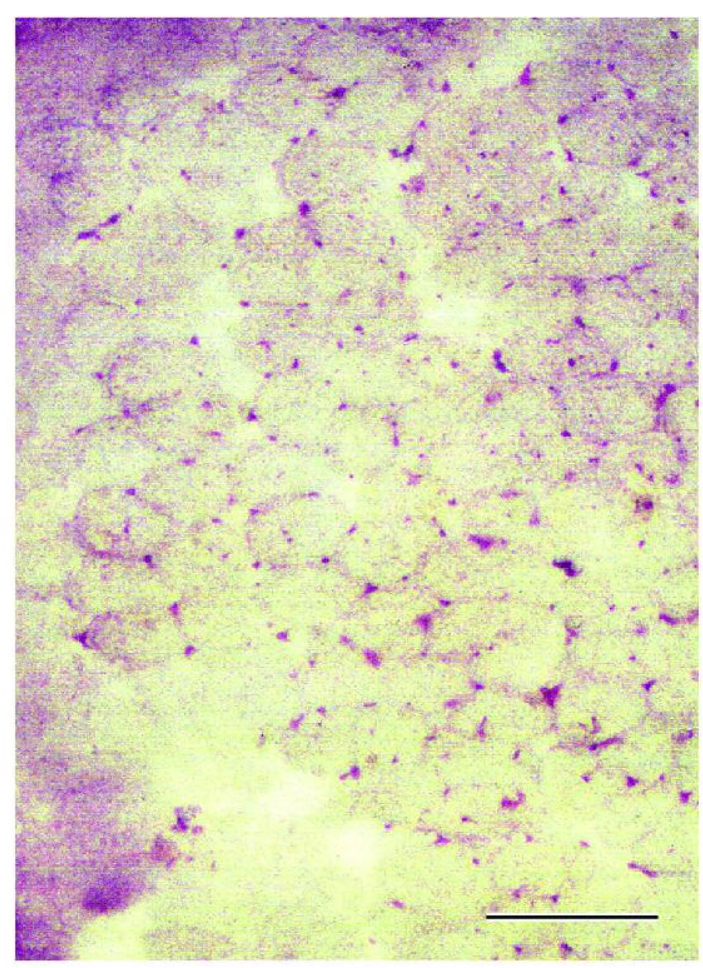

b

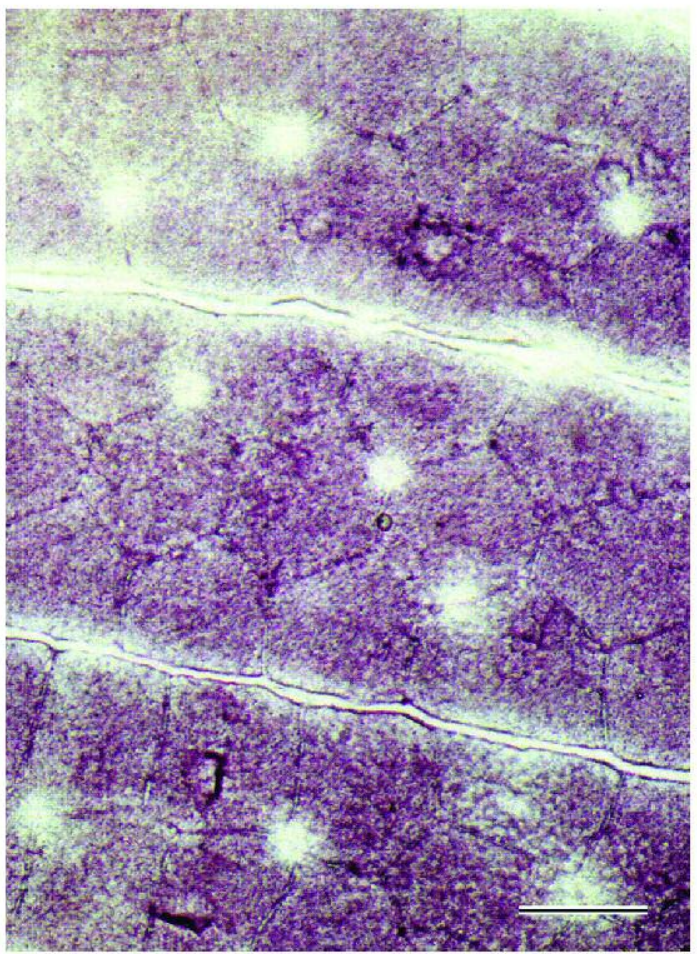

d

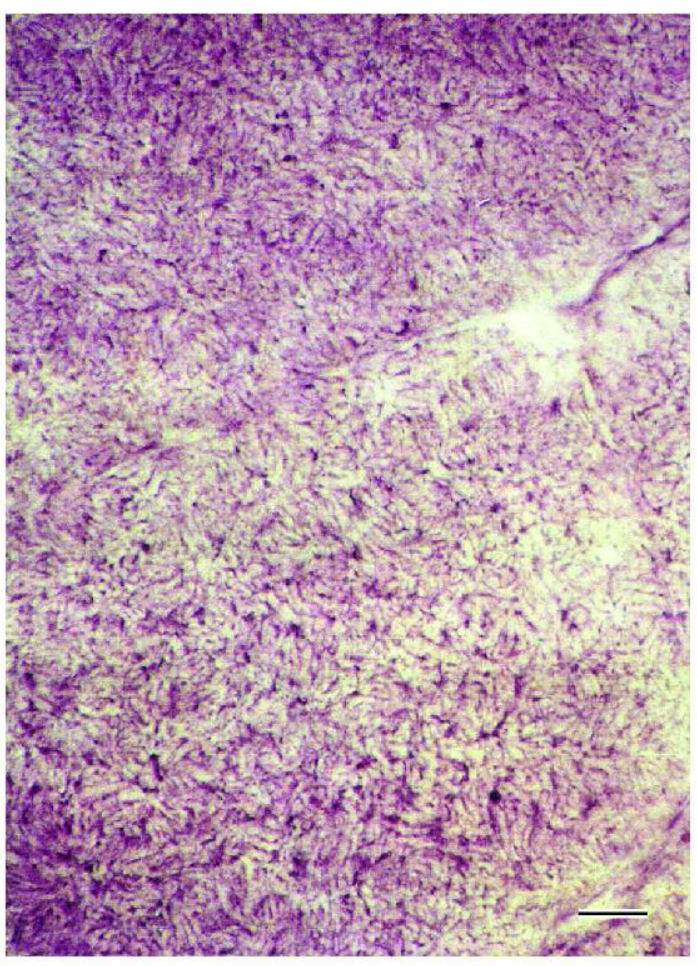

Fig.3 